\title{
Towards a more comprehensive assessment of cardiovascular fitness - magnetic resonance augmented cardiopulmonary exercise testing (MR-CPEX)
}

\author{
Bejal Pandya*, Grzegorz T Kowalik, Daniel S Knight, Oliver Tann, Graham Derrick, Vivek Muthurangu \\ From 16th Annual SCMR Scientific Sessions \\ San Francisco, CA, USA. 31 January - 3 February 2013
}

\section{Background}

Assessment of exercise intolerance is important in patients with cardiovascular disease. Traditionally, this is achieved by measuring maximum VO2 during cardiopulmonary exercise testing (CPEX). However, this cannot discriminate between cardiac output and tissue extraction problems. A better approach may be to assess VO2 and cardiac output simultaneously (which also allows calculation of tissue extraction). Thus, we developed MR augmented CPEX in which real- time PCMR is performed at the same time as respiratory gas analysis. The purpose of this study was to validate this novel technology.

\section{Methods}

Ten volunteers underwent MR-CPEX in a $1.5 \mathrm{~T}$ scanner using a ramped protocol on an MR compatible Ergometer. All volunteers exercised till exhaustion and the total test period was 9 minutes. Expired gases and respiratory flow data were collected with a calibrated MR compatible respiratory analysis system. Using this data continuous $\mathrm{VO} 2, \mathrm{VCO} 2$ and Ve were calculated for the whole test period. Aortic flow was measured continuously during the test period using real-time UNFOLD-SENSE spiral PCMR (spatial resolution: $2.5 \times 2.5 \mathrm{~mm}$, temporal resolution: 30 $\mathrm{ms}, 16000$ frames). Flow data was segmented using a semi-automated technique to calculate cardiac output during exercise. Cardiac output and VO2 were used to calculate arterio-venous oxygen content gradient (tissue

\footnotetext{
Cardiac MR, Great Ormond Street Hospital and Institute of Cardiovascular
} Sciences, University College London, London, UK oxygen extraction). All volunteers also underwent traditional bicycle CPEX for comparison.

\section{Results}

MR augmented CPEX was successful in all volunteers with $40 \%$ of participants reaching their anaerobic threshold. The maximum workload reached during MR and conventional CPEX was strongly correlated. $(\mathrm{r}=0.76)$. Mean peak VO2 during MR-CPEX was $19.3 \pm 5.1 \mathrm{ml} / \mathrm{min} / \mathrm{kg}$ and peak VCO2 was $19.6 \pm 5.5 \mathrm{ml} / \mathrm{min} / \mathrm{kg}$. There was an excellent correlation between MR-CPEX peak VO2 and conventional CPEX ( $\mathrm{r}=0.84)$. During MR-CPEX, mean heart rate rose from $76 \pm 14$ to $151 \pm 25 \mathrm{bpm}$, with no change in stroke volume. This resulted in mean cardiac output increasing from $3.2 \pm 0.5 \mathrm{l} / \mathrm{min} / \mathrm{m} 2$ to $6.6 \pm 1.21 / \mathrm{min} / \mathrm{m} 2$. Mean peak arterio-venous oxygen gradient calculated from the cardiac output and VO2 during MR-CPEX was $12 \mathrm{ml} \mathrm{O} 2$ per $100 \mathrm{ml}$ of blood. Representative ventilation, cardiac output and tissue arterio-venous oxygen gradient curves are shown in figures 1 \&2.

\section{Conclusions}

This study shows that MR-CPEX is a viable technique that can provide a comprehensive assessment of all the components of exercise physiology. During MR-CPEX only submaximal exercise is possible, both due to movement limitation and lack of stroke volume augmentation in the supine position. Nevertheless, there was as strong correlation between traditional CPEX and MR-CPEX. This implies that MR-CPEX does measure useful parameters that are linked to maximal exercise. We believe that the ability to fully measure the cardiopulmonary and peripheral response to exercise will 


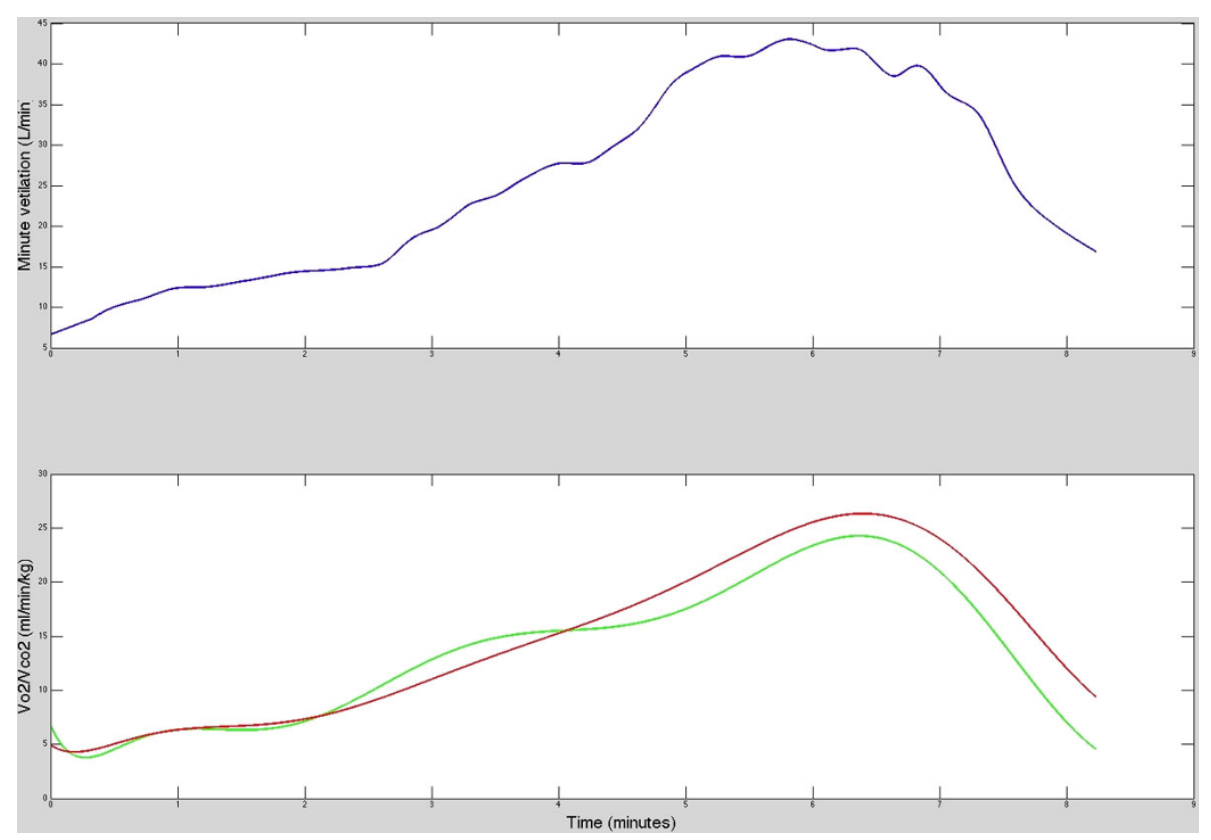

Figure 1 Ventilation (top) and simultaneous VO2 (green) NCO2 (red) curves during MR-CPEX in a volunteer achieving their anaerobic threshold.

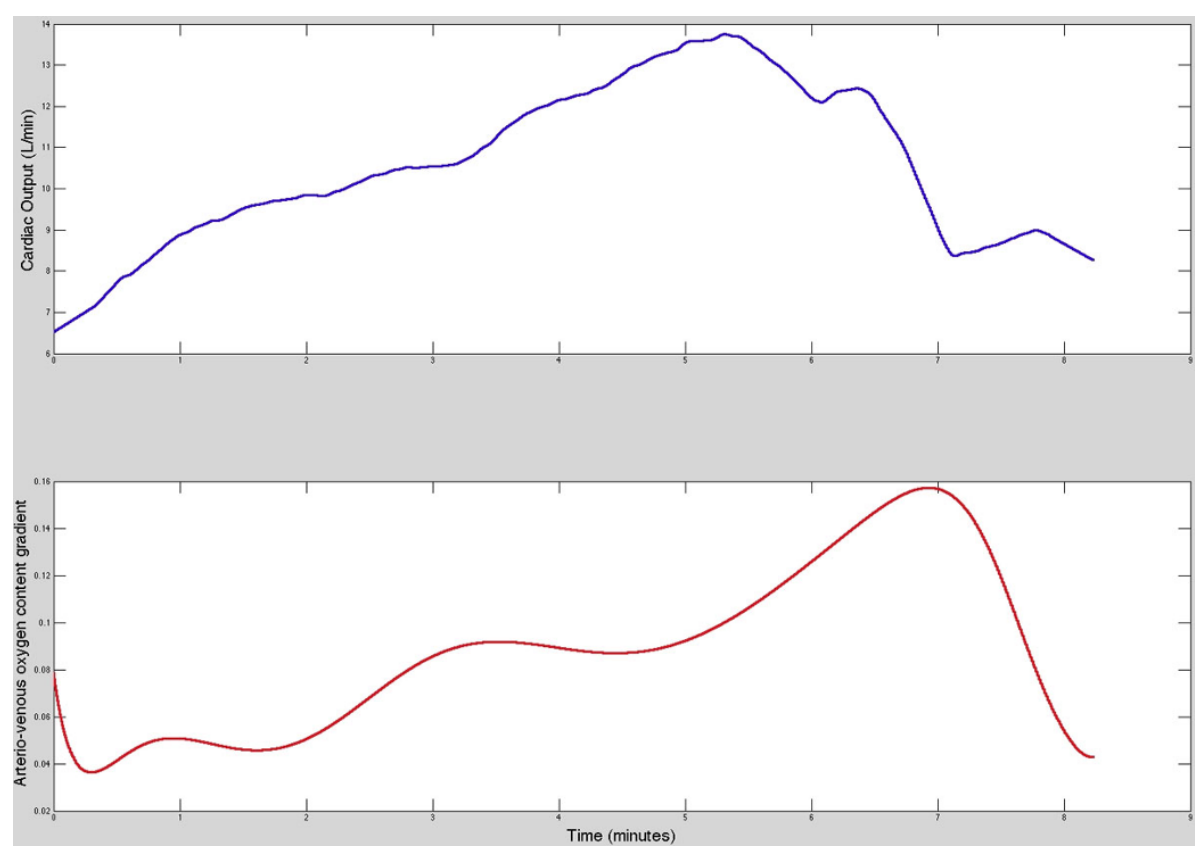

Figure 2 Arterio-venous Oxygen content gradient (top) and Cardiac Output (bottom) during MR-CPEX.

allow better assessment of exercise intolerance in many cardiac diseases.

\section{Funding}

British Heart Foundation Project Grant. Dr Vivek Muthurangu and Dr Bejal Pandya. 
doi:10.1186/1532-429X-15-S1-P58

Cite this article as: Pandya et al:: Towards a more comprehensive assessment of cardiovascular fitness - magnetic resonance augmented cardiopulmonary exercise testing (MR-CPEX). Journal of Cardiovascular Magnetic Resonance 2013 15(Suppl 1):P58.

Submit your next manuscript to BioMed Central and take full advantage of:

- Convenient online submission

- Thorough peer review

- No space constraints or color figure charges

- Immediate publication on acceptance

- Inclusion in PubMed, CAS, Scopus and Google Scholar

- Research which is freely available for redistribution

Submit your manuscript at www.biomedcentral.com/submit 